\title{
EVALUATION OF SALIVARY AND SERUM ANTI-HELICOBACTER PYLORI IN EGYPTIAN PATIENTS WITH H. PYLORI RELATED GASTRIC DISORDERS
}

By

\author{
EFFAT ABD EL-MONEM EL-FAKHFAKH ${ }^{1}$, IMAN FAWZY \\ MONTASSER $^{1^{*}}$, and REHAM ALI AHMED KHALIFA ${ }^{2}$
}

Department of Tropical Medicine ${ }^{1}$, and Department of Microbiology and Immunology ${ }^{2}$, Faculty of Medicine, Ain Shams University, Cairo 11566, Egypt

\begin{abstract}
Helicobacter pylori is a common and important transmissible bacterial human pathogen. Although several diagnostic tests are available for the detection of $H$. pylori infection, all of them have both advantages and disadvantages, and none can be considered as a single gold standard. Serological methods analyzing (serum and saliva) by using enzyme immunoassays, which are simple, reproducible and inexpensive, can detect either antigen or antibody.

This study evaluated the frequency of anti- $H$. pylori serum and salivary antibodies positivity among Egyptian patients with gastric disorders and the validity of salivary, serum serological tests for diagnosis of $H$. pylori, comparing this with gold standard tests performed on endoscopy biopsy. This prospective, case-controlled study included 45 Egyptian patients who attended Ain Shams University Hospitals Cairo, Egypt between January 2013 and June 2013.

There were 29 males \& 16 females their mean age was $51.78 \pm 7$ (range 18-60). Among the ulcerogenic drugs, Aspirin was the most common drug (46.7\%). The evidence revealed the sensitivity of Rapid Urease Test (RUT) was $100 \%$, specificity was $71.4 \%$, Positive Predictive value (PPV) was $88.6 \%$ and Negative Predictive value (NPV) was $100 \%$. The sensitivity of serum IgG was $68.97 \%$ and specificity was $42.86 \%$; while the sensitivity of serum IgA was $89.6 \%$ and the specificity was $50 \%$. Correlating the salivary IgG results with $H$. pylori status diagnosed by culture, salivary IgG succeeded to diagnose 19 cases from the 31 positive $H$. pylori patients with a sensitivity of $63.33 \%$ \& specificity of $92.86 \%$ whereas the results of salivary IgA showed a sensitivity of $80 \%$ and specificity of $92.86 \%$.
\end{abstract}

Keywords: Patients, Helicobacter pylori, salivary immunoglobulins, gastritis.

\section{Introduction}

Helicobacter pylori is the first formally recognized bacterial carcinogen and is one of the common human pathogens, as over half of the world's population is colonized with this gram-negative bacterium. Unless treated, colonization usually persist lifelong (Kusters et al, 2006). However, the prevalence of infection varies geographically ranging from 20 to $50 \%$ in industrialized countries to over $80 \%$ in developing countries (Dzierzanowska, 2006). Since H. pylori was first isolated from human gastric biopsy material in 1983, the gold standard diagnostic test has remained histological analysis and culture for antral biopsy specimen, these technique was invasive and may take 24-72 hours, and therefore there is a need for good serological test that would avoid need for endoscopy (Christie et al, 1996).

Serological testing is the most widely available test for detection of $H$. pylori with relatively high negative predictive value. Serology not affected by local changes in stomach that could lead to false negative results in other tests. Furthermore in patients treated with Proton pump inhibitors (PPIs), if it not possible to stop them for at least two weeks validated IgG serology test (ELISA) mught be used (Tonkic et al, 2012).

Sensitivity and specificity of salivary tests have indicated that saliva could be useful as none invasive technique for detection of $H$. pylori infection (Feteih et al, 2009). There are several methods available for diagnosis of $H$. pylori infection, but none of them is ideal and 
therefore in many clinical situation several tests are needed (Veijola, 2007).

Evaluation of a new salivary tests for diagnosis of $H$. pylori comparing with gold standard evidence of $H$. pylori and with serum serological tests have advantages of being none invasive simple test that can easily performed in the general practice setting; collection is easy for patients and health care personnel and greatly reduces the risk of blood born infection (Christie et al, 1996).

The aim of the study was to evaluate the frequency of anti-H. pylori serum and salivary antibodies positivity among Egyptian patients with gastric disorders and the validity of the new salivary, serum serological tests for diagnosis of $H$. pylori, comparing this with gold standard tests performed on endoscopy biopsy.

\section{Subjects, Materials and Methods}

This prospective, case-controlled study included 45 Egyptian patients who attended Ain Shams University Hospitals Cairo, from January 2013 to June 2013. The study was approved by the Ethics Committee of Ain Shams University Hospitals, Cairo, Egypt in accordance with local research governance requirements. The principle of the study was explained to each patient, with particular highlighting on the steps of the work and patients sign of acceptance.

Inclusion Criteria: Adult Egyptian patients, 18-60 years old with symptoms suggestive of gastritis, peptic ulcer,

Exclusion Criteria: Recent use of medication (within month) for H. pylori related disorders, and ever co-morbidity as end stage renal disease and heart failure.

The primary outcome measures were 1- Assessment of the impact of different anthropometric measures on clinical, endoscopic and pathological severity of GERD in Egyptian patients, 2- The relation between serum leptin and clinical, endoscopic and pathological severity of GERD in Egyptian patients.

Sample size of 45 candidates was selected with study power of $80 \%$, significance criterion of 0.05 .
All patients were subjected to: 1- Full history taking and thorough clinical examination. 2- Laboratory investigations including $\mathbf{C B C}$ and Liver function tests (ALT, AST, total bilirubin, albumin, prothrombin time $\&$ concentration). 3- Upper endoscopy using fibro-optic endoscopy (Pentex A 11038). Thorough examination of the esophagus, stomach and duodenum any lesion was documented. 4- Endoscopic biopsies were taken by the standard biopsy forceps from the antrum of the stomach or any luscious lesions and transported in transport media prepared (Siu et al, 1998), sterile broth that contained brain heart infusion (Oxoid, Basingstoke, United Kingdom) broth with horse serum (5\%), yeast extract $(0.25 \%), 6 \mathrm{mg}$ of vancomycin per liter, $4 \mathrm{mg}$ of amphotericin B per liter, and 20mg of nalidixic acid per liter (BHI-VAN). Then specimens were taken for the following bacteriological \& serological tests:

Rapid Urease Test (RUT): Biopsy of gastric antrum was used to detect urease activity of H. Pylori in gastric mucosal biopsies via color $(\mathrm{PH})$ change resulting from the breakdown of urea by urease into ammonia. This was done using HelicotecUT Plus paper Rapid Urease test kit (Strong Biotech Corporation, Taiwan). Diagnosis by HelicotecUT Plus was interpreted within 5 min up to one hour, yellow color represented negative result and change to pink or magenta represented positive result.

Culture and Sensitivity: Culture material was done on selective media, BD Helicobacter media (Becton Dickinson Diagnostic systems - Heidelberg/ Germany), and determination of antibiotic sensitivity pattern to first line anti-Helicobacter antibiotics clarithromycin and amoxicillin, second line antibiotics as tetracycline and third line antibiotics as levofloxacin by disc diffusion method using the following discs clarithromycin (CLR) $(15 \mu \mathrm{g})$, amoxicillin (AML) $(10 \mu \mathrm{g})$, tetracycline (TE) $(30 \mu \mathrm{g})$ and levofloxacin (LE) $(5 \mu \mathrm{g})$ supplied by Oxoid, England, and also using Hi-Comb test strips with concentrations CLR (240-0.001 $\mu \mathrm{g})$, AML (240-0.001 $\mu \mathrm{g})$, 
TE $(240-0.01 \mu \mathrm{g})$ and LE $(240-0.005 \mu \mathrm{g})$ supplied by Hi-media, India.

Test Procedure: Biopsy specimen's grinded or minced using sterile scalpel with a small amount of sterile physiological saline before they are applied to the medium. The homogenate placed immediately on the medium surface and should be caught with the sterile loop and then streaked over the surface using streak method.

The inoculated plates were incubated for 3 to 5 days at $35 \pm 2{ }^{\circ} \mathrm{C}$ in a microaerobic atmosphere, e.g. in a GasPak jar with an atmosphere provided by using the Anaeogen GasPak, Oxoid, England. After incubation, the plates showed isolated colonies in the areas where the inoculum was appropriately diluted. Helicobacter pylori colonies are tiny to medium-sized and translucent. A Gram stain from respective colonies revealed Gram negative, slightly curved rods. Final identification was done using appropriate biochemical tests. A positive urease, oxidase, and catalase reaction were indicative of $H$. pylori.

Serum and salivary $H$. pylori $\operatorname{IgG}$ and $\operatorname{IgA}$ by using ELISA: Blood samples were collected by venipuncture in $10 \mathrm{ml}$ evacuated tubes containing EDTA or heparin, with the usual precautions. Serum samples were stored at temperatures of $-20^{\circ} \mathrm{C}$. Salivary samples saliva was collected on the day of endoscopy by asking every participant to spit any accumulated saliva into a graded sterile container. Saliva was then spun and stored at $-20{ }^{\circ} \mathrm{C}$ until analyzed.

Samples were diluted (1/100) for Serum: 1$0.010 \mathrm{ml}(10 \mu \mathrm{l})$ of each patient specimen was dispensed into $1 \mathrm{ml}$ of serum diluent. Covered and mixed thoroughly by inversion, and stored at $2-8{ }^{\circ} \mathrm{C}$ for up to $48 \mathrm{hrs}$. 2- Salivary samples not diluted. 3- The microplates' well was formatted for each serum reference, control and patient specimen to be assayed in duplicate. Any unused micro-well strips were back into the aluminum bag, sealed and stored at $2-8^{\circ} \mathrm{C} .4-0.025 \mathrm{ml}(25 \mu \mathrm{l})$ of appropriate serum reference, control and patient specimen was pipetted into the assigned wells for $\operatorname{IgG}$ determination. For $\operatorname{IgA} 0.050 \mathrm{ml}$
$(50 \mu 1)$ of the appropriate serum reference, control or diluted patient specimen was pipetted into the assigned wells. $5-0.100 \mathrm{ml}(100$ $\mu \mathrm{l})$ of $H$. pylori Biotinylated conjugate solution was added. 6- Microplate gently swirled for 20-30 seconds to mixed, covered and incubated 60 minutes at room temperature. 7The contents of microplates were discarded by decantation or aspiration. If decanting, the plate was dried with adsorbent paper. 8- 30 $\mu 1$ of wash buffer was added, decanted or aspirated. Repeat 2 additional times for total of 3 washes. 9- $0.100 \mathrm{ml}(100 \mu \mathrm{l})$ of enzyme antih-IgG, IgA Conjugate Solution was added to all wells. 10- Microplate swirled gently, covered and incubated for 30 minutes at room temperature. 11- Steps 5, 6 were repeated. 12$0.100 \mathrm{ml}(100 \mu \mathrm{l})$ of working substrate solution was added to all wells and incubated for 15 minutes at room temperature. $13-0.050 \mathrm{ml}$ $(50 \mu \mathrm{l})$ of stop solution was added to each well and the microplate swirled gently for 15-20 seconds to mix. 14- Absorbance in each well was read at $450 \mathrm{~nm}$ in microplate reader.

Interpretation: IgG and IgA antibodies to $H$. pylori was confirmed when the serum level exceeds $20 \mathrm{U} / \mathrm{ml}$.

Statistical analysis: Data was IBM computer using SPSS as follows: Description of quantitative variables in form of mean and standard deviation; Description of qualitative variables in form of frequency and percentages. Unpaired t test ( $t$ value) was used to compare a quantitative variable between two independent groups in parametric data. Mann Whitney test ( $Z$ value) was used instead of $t$ test to compare a quantitative variable between 2 independent groups when data is non-parametric (SD $>25 \%$ of mean). Chi Square test (X2 value) was used to compare a qualitative variable between 2 independent groups. Spearman correlation test (rho value) was used to rank different non parametric variables against each other's either positively or inversely. $\mathrm{P}$ value (non-significant if $>0.05$, significant if $<0.05$. Sensitivity (ability to detect + ve cases) $=$ true + ve $/$ (true + ve + false -ve). Specificity_(ability to exclude ve cases $)=$ true - ve / (true - ve + false + ve). Positive predictive value $(\mathrm{PPV})=$ percent of true + ve to all + ve cases. Negative predictive 
value $(\mathrm{NPV})=$ percent of true - ve to all - ve cases.

\section{Results}

The patients were 29 males \&16 females with mean age of $51.78 \pm 7$ (range 18-60). The patients $(60 \%)$ live in rural areas, $31.1 \%$ were smokers and 22.2\% were alcoholics. Aspirin was the most common drug (46.7\%), followed by NSAIDs $(26.7 \%)$. The endoscopy of patients showed more than one findings, which varied from reflux esophagitis in 25 $(55.6 \%)$, congestive gastropathy in 20 (44.4\%), esophageal varices in $14(31.1 \%)$, gastritis in $23(51.11 \%)$, duodenitis in 17 $(37.78 \%)$, gastric ulcer in $3(6.7 \%)$ and duodenal ulcer in $10(22.2 \%)$ patients (Tab. 1$)$.

Culture positive (Tab. 2) was found in 31 (68.9\%) patients and negative in 14 (31.1\%). While sensitivity to clarithromycin was $(54.84 \%)$, to amoxicillin was $(38.71 \%)$, to tetracycline was $(80.65 \%)$ and to levofloxacin was $(70.97 \%)$.

Rapid urease test was positive in 35 patients $(77.8 \%)$ and negative in $10(22.2 \%)$. The serum and salivary $H$. pylori antibodies (Tab. 3) showed serum IgG positivity in 28patients $(65.12 \%)$, serum IgA positivity in 33 (76.74\%), while salivary IgG positivity in 20 patients $(45.45 \%)$ and salivary $\operatorname{IgA}$ positivity in $25(56.82 \%)$. Comparison between rapid urease test and culture showed sensitivity of RUT was $100 \%$, specificity was $71.4 \%$, PPV was $88.6 \%$ and NPV was $100 \%$. Correlated serum IgG with $H$. pylori diagnosed by culture, serum IgG diagnosed $20 / 31$ positive patients with $68.97 \%$ sensitivity, 71.43 PPV, $42.86 \%$ specificity and $40 \%$ NPV. Serum IgA diagnosed 26/31 positive patients with $89.66 \%$ sensitivity \& $78.79 \%$, PPV also specificity was $50 \%$ \& NPV $70 \%$. Salivary IgG diagnosed 19 out of 31 positive patients with 63.33\% sensitivity, 95\% PPV, 92.86\% specificity \& NPV $54.17 \%$. Salivary diagnosed $24 / 31$ positive patients with $80 \%$ sensitivity, 96\% PPV, 92.86\% specificity and $68.42 \%$ NPV (Tab. 4).

Table 1: Endoscopic finding in the studied patients. $\dagger$

\begin{tabular}{|l|c|c|}
\hline Variables & Number $(\mathrm{N}=45)$ & Percentage\% \\
\hline GERD & 25 & 55.6 \\
\hline Gastritis & 23 & 51.1 \\
\hline Duodenitis & 17 & 37.7 \\
\hline Peptic ulcer disease: & & \\
\hline Gastric ulcer & 3 & 6.7 \\
\hline Duodenal ulcer & 10 & 22.2 \\
\hline Congestive gastropathy & 20 & 44.4 \\
\hline Esophageal varices & 14 & 31.1 \\
\hline No abnormality detected & 3 & 6.6 \\
\hline
\end{tabular}

$\mathrm{GERD}=$ Gastroesophageal Reflux disease, $\uparrow$ Values $=$ number (percentage) .

Table 2: Culture and antibiotic sensitivity test in the study group $\dagger$

\begin{tabular}{|l|c|c|}
\hline Variables & Number $(\mathrm{N}=45)$ & Percentage \% \\
\hline Positive & 31 & 68.9 \\
\hline Antibiotic sensitivity: & & \\
\hline Clarithromycin & \\
- Sensitive & 17 & 54.84 \\
- Resistance & 14 & 45.16 \\
\hline Amoxicillin & & \\
- Sensitive & 12 & 38.71 \\
- Resistance & 19 & 61.29 \\
\hline Tetracyclin & & \\
- Sensitive & 25 & 80.65 \\
- Resistance & 6 & 19.35 \\
\hline Levofloxacin & & \\
- Sensitive & 22 & 29.97 \\
- Resistance & 9 & \\
\hline
\end{tabular}


Table 3: Rapid urease test, serum and salivary H. pylori antibodies (IgG, IgA) in patients. $\dagger$

\begin{tabular}{|l|c|c|}
\hline Variables & Number & Percentage $\%$ \\
\hline RUT positive & 35 & 77.8 \\
\hline Serum H. pylori antibodies (positivity)* $^{*}$ & & \\
- IgG & 28 & 65.12 \\
- IgA & 33 & 76.74 \\
\hline Salivary H. pylori antibodies (positivity)** & & \\
- IgG & 20 & 45.45 \\
- IgA & 25 & 56.82 \\
\hline
\end{tabular}

RUT $=$ rapid urease test, ${ }^{*}$ Serum $(\operatorname{IgG}, \operatorname{IgA})$ for 43 patients $\left(2\right.$ patients refused). ${ }^{* *}$ Salivary (IgG, IgA) for 44 patients (1 patient refused).

Table 4: Validity of rapid urease test, serum and salivary of IgG \& IgA tests in relation to culture.

\begin{tabular}{|l|c|c|c|}
\hline \multirow{2}{*}{ Variables } & \multicolumn{2}{|c|}{ Culture } & Total $^{*}$ \\
\cline { 2 - 4 } & Negative & Positive & \\
\hline RUT: & & & 10 \\
\hline Negative & 10 & 0 & 35 \\
\hline Positive & 4 & 31 & \\
\hline Serum IgG*: & & & 15 \\
\hline Negative & 6 & 9 & 28 \\
\hline Positive & 8 & 20 & 10 \\
\hline Serum IgA*: & & & 23 \\
\hline Negative & 7 & 3 & \\
\hline Positive & 7 & 26 & 24 \\
\hline Salivary IgG**: & & & 20 \\
\hline Negative & 13 & 11 & \\
\hline Positive & 1 & 19 & 25 \\
\hline Salivary IgA**: & & & 19 \\
\hline Negative & 13 & 6 & \\
\hline Positive & 1 & 24 & \\
\hline
\end{tabular}

*Serum (IgG, IgA) done for 43 patients (2 patients refused), ${ }^{* *}$ Salivary (IgG, IgA) done for 44 patients (1 patient refused).

\section{Discussion}

Helicobacter pylori is a common and important transmissible bacterial human pathogen. This infection varies worldwide being as low as $10 \%$ in developed western nations to more than $80 \%$ among many developing countries. The infection primarily involves the upper gastrointestinal tract causing progressive acute and chronic gastro-duodenal inflammation (Thirumurthi and Graham, 2012).

Although several diagnostic tests are available for the detection of $H$. pylori infection, all of them have both advantages and disadvantages, and none can be considered as a single gold standard. A combination of endoscopic biopsy-based methods (such as rapid urease testing, histologic examination, cul- ture, and PCR) usually gives the most reliable diagnosis. These methods are invasive, expensive, and not always applicable. Thus, there is an increasing interest in non-invasive tests for $H$. pylori detection. Several tests have been developed and introduced into clinical practice: urea breath tests, stool antigen tests, and serologic tests (Dzieranowska et al, 2006). Serology of serum and saliva by using enzyme immunoassays are simple, reproducible and inexpensive and detect either antigen or antibody. Although serum-based enzyme immunoassay was used to detect $H$. pylori infection, but cannot distinguish between past and present infections as titers decline very slowly even after $H$. pylori treatment (Estakhri et al, 2008). Saliva offers advantages over serum as easy collected, noninvasive, 
and less hazardous, and there is a greatly reduced risk of blood-borne infections and suitable for children (Krishnaswamy et al, 2012).

In the current study, the $H$. pylori infection in the presented patients reached up to $68.9 \%$. This percentage is comparable to $68.4 \%$ reported in Oman (Al Balushi et al, 2013). But, in Canada from $7.1 \%$ up to $23.1 \%$ were reported (Chair et al, 2010), which may be due to the difference in environment and socioeconomic conditions.

Yucel et al. (2008) reported a slightly higher incidence of $H$. pylori infection in females, but Sasidharan et al. (2012) found that the prevalence rate among males was significantly higher than for females. On the other hand, Zhubi et al. (2010) and Alo et al. (2013) went with the present results that there was no gender predominance.

In this study, no significant difference was found between $H$. pylori positive and negative in terms of patients' symptomatology. This resukts agreed with Selgrad et al. (2008) who reported that $H$. pylori infection did show association with a specific symptom.

The optimal diagnostic approach in patients with dyspepsia is still controversial. Upper endoscopy is frequently performed as the primary diagnostic test, but being costly, not accepted by many patients and in most patients no underlying disease can be identified. The strategy based on the noninvasive testing for $H$. pylori could be more cost effective. Such a strategy either be imply the referral of only $H$. pylori-positive patients for endoscopy "test and scope" strategy or subjecting $H$. $p y$ lori positive patients to anti- $H$. pylori treatment "test and treat" strategy (Gisbert and Calvet, 2013). On the other hand, a new easy to perform non-invasive diagnostic tests have been introduced; the $H$. pylori serological tests on serum and saliva, highly promising outcome results. Besides, these sero-tests were claimed to be suitable for monitoring $H$. pylori infection, and could be competitive with other non-invasive tests (El-Mekki et al, 2011).
The present work was to evaluate the clinical significance of serum and salivary anti- $H$. pylori antibodies in the diagnosis of human infection, accomplished by correlating the results of serum and salivary antibodies with the results of culture and RUT as standard methods for diagnosis..

Most of studies used more than one diagnostic method as reference standard, as no single available test provides the definitive diagnosis of $H$. pylori by itself. The implication of this is that any infection missed by one test due to the patchy distribution of the infection and consequent sampling error could be easily picked by the other tests, thereby increasing the number of positive results by the reference standard (Jemilohun et al, 2011).

In the present study, the culture and rapid urease test were used as golden standard tests in diagnosing $H$. pylori. This agrees with $\mathrm{Al}-$ Ali et al. (2010) who also used these tests in diagnosing $H$. pylori and also Gosciniak et al. (2003) used culture and rapid urease test as golden standard tests.

Regarding culture and sensitivity examinations for diagnosing $H$. pylori infection, the results showed $H$. pylori positive culture using BD Helicobacter media in 31 patients (68.9\%). This agreed with Asrat et al. (2007) who found $H$. pylori positive culture was (69\%). But, Ibrahim et al. (2012) found that H. pylori positivity culture was $(90 \%)$.

Regarding rapid urease test, it was positive in 35 patients $(77.8 \%)$. This agreed with Menoni et al. (2013) who found that $H$. pylori positivity by RUT was $78 \%$, and $\mathrm{Ou}$ et al. (2013) showed opposition to our results they found $H$. pylori positivity by RUT was only $32.6 \%$.

On the other hand, in the present study the rapid urease test sensitivity gave 31/31 $(100 \%)$ compared to culture results in the current study, while its specificity was 10/14 (71.4\%) compared to culture results. Lustig (2010) reported that RUT sensitivity and specificity were $100 \%$ and $76 \%$ respectively. But, Foroutan et al. (2010) showed RUT sensitivity and specificity were $100 \%$. 
The low specificity of RUT test was explained by increases the possibility of interference from other urease positive bacteria in the gastric mucosa as Klebsiella or Proteus mirabilis (Johannessen et al, 2013). False positive results of RUT in the current study were 4 cases $(12.9 \%)$ compared to culture results. Jemilohun et al. (2011) found false positive results was $11.62 \%$ and they explained these false results to be that thesalivate or have reflux alkaline bile into the stomach could have a weak positive reaction because the liquid may contaminate a small gastric biopsy specimen such that the resulting surface $\mathrm{PH}$ was $>6.0$.

In current study serum $H$. pylori IgG was positive in 28 patients $(65.12 \%)$ and 33 $(76.74 \%)$ for IgA. These results more or less agreed with Keramati et al. (2007) who found the positivity rate of both $\operatorname{IgG}$ and $\operatorname{IgA}$ were (77.8\%). She et al. (2009) showed that the positivity rate of $H$. pylori $\operatorname{IgG}$ was $(35.6 \%)$ and $\operatorname{IgA}$ was $(32.7 \%)$. Also Al-Windi et al. (2013) found IgG positivity rate was (32.3\%) and $\operatorname{IgA}$ positivity rate was $(58.2 \%)$.

In the present work the correlating of serum IgG test to culture results revealed a sensitivity of $68.97 \%$ and a specificity of $42.86 \%$. On other hand, Khalilpour et al. (2013) found that sensitivity and specificity of serum IgG reach up to $100 \%$ for both. On the other hand, She et al. (2009) found IgG sensitivity of $88.6 \%$ and specificity of $46.2 \%$.

The present results showed sensitivity of serum $\operatorname{IgA}(89.66 \%)$ and a specificity of $(50 \%)$, which results are comparable to study of Sudraba et al. (2011) who found sensitivity of $(96 \%)$ and specificity of $(50 \%)$. She et al. (2009) found sensitivity of IgA (73.8\%) and specificity $(48.8 \%)$. On the other hand, Kienesberger et al. (2012) showed higher specificity (82\%) and lower sensitivity (61\%).

In the present study, anti-H. pylori IgG and anti-H. pylori IgA sensitivity were moderately higher than specificity. This agreed with Bolad et al. (2011) who found high sensitivity and low specificity making the accuracy of this test moderately satisfactory. Though
ELISA was moderately high sensitive it might not be reliable for diagnostic purposes in some but not all patients due to its low specificity.

The current study showed salivary antibodies IgG positive in 20 patients $(45.45 \%)$ and IgA positive in 25 patients (56.82\%) Estakhri et al. (2008) reported that salivary H. pylori IgG positivity was $(44.75 \%)$. While, Golpak et al. (2013) reported that salivary H. pylori IgG positivity was $(2.9 \%)$. In another study Guzik et al. (2004) reported salivary IgA positivity of 54\%, but Feteih et al. (2009) reported $37.2 \%$.

In the present work, the salivary IgG test revealed a sensitivity of $(63.33 \%)$ and specificity of $(92.86 \%)$. These results partially agred with Leal et al. (2008) who found also low sensitivity (69.1\%) and high specificity $(94.7 \%)$ of salivary IgG. On other study, ElMekki et al. (2011) reported a high sensitivity $(95 \%)$ and low specificity (70\%) of salivary IgG. Also, Krishnaswamy et al. (2012) found that the salivary IgG sensitivity and specificity were $(79.31 \%)$ and $(63.64 \%)$ respectively.

In the present study, the salivary IgA test revealed a sensitivity of $80 \%$ and specificity of $92.86 \%$; but Kabir (2003) reported low sensitivity and specificity $76 \%$ and $61 \%$ respectively, and Feteih et al. (2009) reported low sensitivity and specificity (41.7\%) and (61\%) respectively.

In this study, serum and salivary IgA more correlated with culture and RUT than IgG this agreed with Al-Windi et al. (2013). On other hand She et al. (2009) found that IgG has better correlation with gold standard than $\operatorname{IgA}$, while, Harris et al. (2005) found that IgA to be equal to $\mathrm{IgG}$ in performance.

In the study using salivary antibodies in diagnosis of $H$. pylori gave more sensitivity and specificity than serum antibodies. This agreed with Estakhri et al. (2008) who found sensitivity and specificity of serum was more than saliva, but Leal et al. (2008) found there was very slight difference between both tests in saliva and serum. 


\section{Conclusion}

The use of $H$. pylori salivary antibodies test is safe and easily performed. Invasive diagnostic tests (culture and rapid urease) are still more sensitive and specific; however, salivary serological testing may have a role in epidemiological studies and in screening dyspeptic patients in general practice. Extensive study to evaluate salivary antibodies as screening test prior to endoscopy or for monitoring the response to therapy is ongoing and will be published later on.

\section{References}

Al-Ali, J, Al-Asfar, F, Dhar, R, et al, 2010: Diagnostic performance of gastric imprint smear for determination of Helicobacter pylori Infection. Can. J. Gastroenterol. 24, 10:603-6.

Al-Balushi, MS, Al-Busaidi, JZ, Al-Daihaniet, MS, et al, 2013: Sero-pre-valence of Helicobacter pylori infection among asymptomatic healthy Omani blood donors. Asian Pacific J. Trop. Dis. 3, 2:146-9.

Alo, MN, Alhassan, HM, Saidu, AY, et al, 2013: The prevalence of Helicobacter pylori infection in asymptomatic persons in Ethiopia East Local Government Area, Delta State, Nigeriamore. Int. J. Publ. Hlth. Pharm. 1, 1:115-9.

Al-Windi, A, Hussain, A, Hattem, A, Salih, N, 2013: Seroprevalence of anti-Helicobacter pylori antibodies in population of Sulaimani Governorate/ Kurdistan Region/Iraq. J. Zankoy Sulaimani 15, 3:175-85.

Asrat, D, Endale, K, Yohannes, M, et al, 2007: Comparison of diagnostic me-thods for detection of Helicobacter pylori infection in different clinical samples of Ethiopian dyspeptic patients. Austral-Asian J. Cancer 6, 4:231-7.

Bolad, A, Lutfi, M, Seif Eldein, S, et al, 2011: Conditional ratios of anti-Helicobacter pylori $\operatorname{IgG}$ and $\operatorname{IgA}$ in detection of chronic urticarial and other skin lesions. J. Sci. Tech. 12, 1:64-9.

Chair, RH, Xiao, SD, Megraud, F, et al, 2010: Helicobacter pylori in Developing Countries. Wld.Gastroenterol. Organ. 23:1-15.

Christie, JML, McNulty, CAM, Shepherd, NA, et al, 1996: Is saliva serology useful for diagnosis of Helicobacter pylori? GUT 39:27-30.

Dzieranowska, K, Philippe, L, Francis, M, et al, 2006: Diagnosis of Helicobacter pylori infection. Helicobacter 11, 1:6-13.
El-Mekki, A, Kumar, A, Alknawy, B, et al, 2011: Comparison of enzyme immunoassays detecting Helicobacter pylori specific igg in serum and saliva with endoscopic and biopsy findings in patients with dyspepsia. Indian J. Med. Microbiol. 2, 2:136-40.

Estakhri, R, Dolatkhah, H, Ghazan- chaei, A, et al, 2008: Saliva or Serum, which is better for the Diagnosis of Gastric Helicobacter pylori Infection? Iranian J. Clin. Infect. Dis. 3, 3:121-5.

Feteih, R, Abdel-Salam, M, Jamjoom, H, et al, 2009: Salivery Anti-Heli-cobacter pylori positivity among endoscopy patients with chronic liver disease. East. Mediterr. Hlth. J. 15, 6:1371-8.

Foroutan, M, Loloei, B, Irvani, S, et al, 2010: Accuracy of rapid urease test in diagnosing Helicobacter pylori infection in patients using NSAIDs. Saudi J. Gastroentrol. 16, 2:110-2.

Gisbert, J, Calvet, X, 2013: Helicobacter pylori "Test-and-Treat"' strategy for management of dyspepsia: A comprehensive review. Clin. Translat. Gastroenterol. 4, 32:1-17.

Golpak, Y, Joshaia, N, Beatrice, S, et al, 2013: using enzyme immunoassy to assess the prevalence of Helicobacter pylori IgG in saliva and blood plasma. Pacific J. Med. Sci. 11, 2:40-50.

Gosciniak, G, Przondo-Mordarska, A, Iwanczak, B, et al, 2003: Helicobacter pylori antigens in stool specimens of gastritis children before and after treatment. J. Pediatr. Gastroenter. Nutr. 36: 376-80.

Guzik, M, Karczewska, E, Bielanski, W, et al, 2004: Association of the presence the Helicobacter pylori in the oral cavity and in the stomach. J. Physiol. Pharmacol. 55, 2:105-15.

Harris, P, Perez, G, Zylberberg, A, et al, 2005: Relevance of adjusted cut-off values in commercial serological immunoassays for Helicobacter pylori infection in children. Dig. Dis. Sci. 50:2103-9.

Ibrahim, NH, Gomaa, AA, Abu-Sief, MA, et al, 2012: The Use of different laboratory methods in diagnosis of Helicobacter pylori infection; a comparative study. Life Sci. J. 9, 4:249-59.

Jemilohun, AC, Otegbayo, JA, Ola, S O, et al, 2011: Diagnostic accuracy of rapid urease test for the diagnosis of Helicobacter pylori in gastric biopsies in the Nigerians with dyspepsia. African J. Clin. Exp. Microbiol.12, 2:62-6.

Johannessen, R, Kare, B, Constantin, J, et al, 2013: PCR versus culture in the diagnosis of $\mathrm{Hel}$ icobacter pylori infection. Gastroenterol. Insights 5:1-6. 
Kabir, S, 2003: Review article: Clinic-based testing for Helicobacter pylori infection by enzyme immunoassay of feces, urine and saliva. Alimen. Pharmacol. Thera. 17: 1345-54.

Keramati, MR, Siadat, Z, Mahmoudi, M, 2007: The Correlation between H. pylori infection with serum ferritin concentration and iron deficiency anemia. Int. J. Hematol. Oncol. 17, 1:16-20.

Khalilpour, A, Santhanam, A, Wei, C, et al, 2013: Antigenic proteins of Helicobacter pylori of potential diagnostic value. Asian Pacific J. Cancer Prevent. 14, 3:1635-42.

Kienesberger, S, Guillermo, P, Juan, RC, et al, 2012: Serologic Host Response to Helicobacter pylori and Campylobacter jejuni in socially housed Rhesus Macaques (Macaca mulatta). Gut Path. 4:1-9.

Krishnaswamy, R, Thirumala, C, Manoranjini, $\mathbf{D}$, et al, 2012: Salivary $\operatorname{IgG}$ assay to detect Helicobacter pylori infection in an Indian adult population. Indian J. Dent. Res. 23, 5:694-5. Kusters, JG, Arnoud, H, Vliet, M, Kupers, EJ, 2006: Pathogenesis of Helicobacter pylori Infection. Clin. Microbiol. Rev. 19, 3:449-90.

Daniel, L, 2010: GI Infections with an Initial. J. Pediatr. Gastroenterol. Nutr. 50, 4:400-3.

Menoni, S, Ferreira, M, Bonon, SH, Alves, ZJ, Murilo, R, et al, 2013: PCR-Based detection and genotyping of Helicobacter pylori in endoscopic biopsy samples from Brazilian Patients. Gastroenterol. Res. Pract. 13:1-8.

Ou, Z, Liya, X, Ding-You, L, et al, 2013: Evaluation of a new fluorescence quantitative PCR test for diagnosing Helicobacter pylori infection in children. BMC Gastroenterol.13:1-6.

Sasidharan, S, Batumanathan, G, Ma-nickam, R, et al, 2012: Prevalence of Helicobacter pylori infection among patients referred for endoscopy: Gender and ethnic differences in Kedah, Malaysia. Asian Pacific J. Trop. Dis. 12:55-9.

Selgrad, M, Kandulski, A, Malfer- theiner, P, 2008: Dyspepsia and Helicobacter pylori. J. Digest. Dis. 26, 3: 210-4.

She, RC, Andrew, WR, Litwin, CM, 2009: Evaluation of Helicobacter pylori immunoglobulin $\mathrm{G}(\operatorname{IgG}), \operatorname{Ig} \mathrm{A}$, and $\operatorname{IgM}$ serologic testing compared to stool antigen testing. Clin. Vaccine Immunol. 16, 8:1253-5.

Siu, L, Leung, W, Cheng, A, et al, 1998: Evaluation of a Selective Transport Medium for Gastric Biopsy Specimen to be cultured for Helicobacter pylori. J. Clin. Microbiol. 36:3048-50.

Sudraba, A, Daugule, I, Rudzite, D, et al, 2011: Performance of routine Helicobacter pylori tests in patients with atrophic gastritis. J. Gastrointestin Liver Dis. 20, 4: 349-54.

Thirumurthi, S, Graham, D, 2012: Helicobacter pylori infection in India from a western perspective. Indian J. Med. Res. 136:549-62.

Tonkic, A, Tonkic, M, Lehours, P, et al, 2012: Epidemiology and diagnosis of Helicobacter pylori Infection. Helicobacter 17:1-8.

Veijola, L, 2007: New aspects of the diagnosis of Helicobacter pylori infection. Finland. 27-41

Yucel, T, Aygin, D, Sen, S, et al, 2008: Prevalence of Helicobacter pylori and related factors among university students in Turkey. Jpn. J. Infect. Dis. 61:179-83.

Zhubi, BC, Zana, BG, Ymer, MI, et al, 2010: Helicobacter pylori infection according to $\mathrm{ABO}$ group among blood donors in Kosovo. J. Hlth. Sci. 1, 2:83-9. 